\title{
Potentials and possible safety issues of using biorefinery products in food value chains
}

\author{
Lange, Lene; Meyer, Anne S.
}

Published in:

Trends in Food Science and Technology

Link to article, DOI:

10.1016/j.tifs.2018.08.016

Publication date:

2019

Document Version

Peer reviewed version

Link back to DTU Orbit

Citation $(A P A)$ :

Lange, L., \& Meyer, A. S. (2019). Potentials and possible safety issues of using biorefinery products in food value chains. Trends in Food Science and Technology, 84, 7-11. https://doi.org/10.1016/j.tifs.2018.08.016

\section{General rights}

Copyright and moral rights for the publications made accessible in the public portal are retained by the authors and/or other copyright owners and it is a condition of accessing publications that users recognise and abide by the legal requirements associated with these rights.

- Users may download and print one copy of any publication from the public portal for the purpose of private study or research.

- You may not further distribute the material or use it for any profit-making activity or commercial gain

- You may freely distribute the URL identifying the publication in the public portal 


\section{Accepted Manuscript}

Potentials and possible safety issues of using biorefinery products in food value chains

Lene Lange, Anne S. Meyer

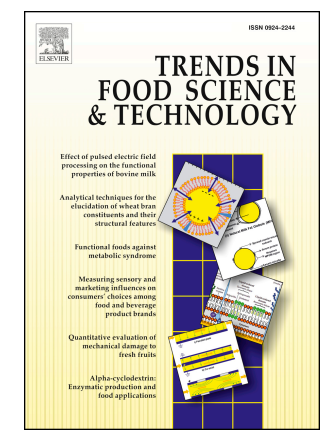

PII:

S0924-2244(18)30538-7

DOI:

10.1016/j.tifs.2018.08.016

Reference: TIFS 2311

To appear in: Trends in Food Science \& Technology

Received Date: 5 August 2018

Revised Date: 18 August 2018

Accepted Date: 31 August 2018

Please cite this article as: Lange, L., Meyer, A.S., Potentials and possible safety issues of using biorefinery products in food value chains, Trends in Food Science \& Technology (2018), doi: 10.1016/ j.tifs.2018.08.016.

This is a PDF file of an unedited manuscript that has been accepted for publication. As a service to our customers we are providing this early version of the manuscript. The manuscript will undergo copyediting, typesetting, and review of the resulting proof before it is published in its final form. Please note that during the production process errors may be discovered which could affect the content, and all legal disclaimers that apply to the journal pertain. 
Elsevier SAFE Special Issue on Trends in Food Safety

\title{
Potentials and possible safety issues of using biorefinery products in food value chains
}

by Lene Lange ${ }^{1, *}$ and Anne S. Meyer ${ }^{2}$

${ }^{1}$ Center for Bioprocess Engineering, Department of Chemical and Biochemical Engineering, Technical University of Denmark, DTU, DK-2800 Kgs. Lyngby, Denmark

${ }^{2}$ Section for Protein Chemistry and Enzyme Technology, Department of Biotechnology and Biomedicine, Technical University of Denmark, DTU, DK-2800 Kgs. Lyngby, Denmark

*Corresponding author, address as above, e-mail: lene.lange2@gmail.com

\begin{abstract}
Background: More than one third of all food produced globally goes to waste. New biorefining and bio-processing approaches can help make higher value products from many more components of large scale agro- and food processes than previously exploited. If we do not take advantage of such new bioprocessing opportunities we will soon be wasting even more and in certain cases miss out on opportunities for producing healthier foods.
\end{abstract}

Scope and Approach: In this short treatise we have selected recent bioprocessing examples that target production of new products from biomass, including plant and marine biomass, and especially from food- and agro-industrial side streams. We have coined these processes and the products from them as having potential since they also encompass improved resource efficiency, getting more value out the raw materials, and lowering of the climate impact of food production per ton produced. These targets go hand in hand with improved industrial competitiveness. A focus on the full use of the biomass, by biological (microbial or enzymatic) processing of residues and sidestreams, can pave the way for production of higher value products, such as food and feed ingredients combined with production of bio-fertilizers and bioenergy.

Key findings and conclusions: The new opportunities for bio-based value chains from the yellow and the green agricultural and forestry bio-refineries, bioprocessing of different types of food- and agroindustrial side-streams and new materials from the blue biomass, e.g. seaweeds, and the red slaughterhouse side-streams are described, exemplified and discussed, and safety issues are addressed.

In conclusion: Increased resource efficiency via targeted biorefining, often employing enzymatic processing, may open the door to improved environmental sustainability and industrial competitiveness. Further, a biorefining agenda can create new jobs. Development of new business models may moreover pave the way for revenue sharing through the entire value chain.

\section{Key Words:}

1. Food and feed ingredients from biorefinery biomass conversion. 2. Increased resource efficiency.

3. Reduction of food waste. 4. New biobased value chains. 5. Strengthened industrial competitiveness. 6 . Safety assessments of ingredients from biomass bioprocessing 


\section{Potentials and possible safety issues of using biorefinery products in food value chains}

Lene Lange ${ }^{1, *}$ and Anne S. Meyer ${ }^{2}$

${ }^{1}$ Center for BioProcess Engineering, Department of Chemical and Biochemical Engineering, Technical University of Denmark, DK-2800 Lyngby, Denmark

${ }^{2}$ Section for Protein Chemistry and Enzyme Technology, Department of Biotechnology and Biomedicine, Technical University of Denmark, DTU, DK-2800 Kgs. Lyngby, Denmark

"Corresponding author, address as above, e-mail: lene.lange2@gmail.com

\section{Current situation}

Close to one third of all food produced globally goes to waste (www.FAO.org/savefood/resources/keyfindings 2018). The United Nations have adopted 17 Sustainable Development Goals to be met by 2030 (http://www.un.org/sustainabledevelopment/sustainable-developmentgoals/2018). The new bioeconomy can potentially contribute to most of these goals by creating basis for improved resource efficiency leading to a more sustainable world. Sustainable Development Goal no. 12 concerns „Responsible consumption and production patterns“- This goal is to promote resource and energy efficiency. In practice this requires change of practice also in the production of foods, i.e. in both agriculture and food processing, notably with respect to reducing the amounts wasted. Reduction of waste can be expanded to the concept of avoiding production of waste-streams or low-value side streams during food and beverage processing and in agro-industrial processes targeting certain food ingredients or compounds such as sugar, starch, or protein isolates. In turn, this expansion currently implies upgrading and targeting production of new products from these side streams as biorefinery products.

The present paper summarizes the current trends, highlights some key biorefinery processing options (with examples of products), and outlines some of the challenges of biorefinery processes and products in food value chains.

Biorefining relates to sustainable processing of biomass to a spectrum of products, i.e. food and feed ingredients, fine chemicals and/or materials and bioenergy. Hence, biorefining implicitly involves improved utilization of biological resources by generating value from all parts of particular biomass feed sources. As indicated above, new biorefining and bioprocessing technologies can help decrease waste by making higher value products from many more feedstock sources and components than what is hitherto exploited e.g. lignocellulosic biomass, industrial side streams of the food and agroindustrial processing industry, and even cut-offs from fish processing (King et al., 2010). Several of the new processes are currently at a proof-of-the-concept stage and are published based on labscale or pilot plant scale experiments (as are several of the examples to be discussed below).

Some of the new biorefinery trends have been driven by governmental strategic investments in industry-academia partnerships for development of green growth options, but many of the current biorefinery trends are also directly driven by commercial incentives. Processing and valorization of side streams has thus become vital for securing market flexibility and competitiveness of many classic large scale food- and agri-processes that produce for example starch, sugar, or vegetable proteins. In addition, as discussed further below, other processes such as beer brewing, cheesemanufacture, and the meat processing industry also focus on side stream upgrading. Value-addition by processing of the low-value byproducts to attain new products, i.e. biorefinery products, can also 
assist in off-setting the prospected increased costs and environmental concerns tied to the disposal of the residue streams. For this reason, companies involved in large scale manufacturing of products such as starch and sugar have already developed biorefining of the side streams to a significant part of the business. For example, by now, the potato is a feedstock to a biorefinery from which a range of value added products are manufactured. In the literature several reports moreover present how production of e.g. potato proteins (Waglay \& Karboune, 2017) and highly prebiotic fibres can be produced by enzymatic processing of the potato starch side-streams (Thomassen et al., 2011). Similarly, sugar beet processing can be seen as a biorefinery, making several value added products beyond the primary sucrose product - by biorefining of the pulp (Holck et al., 2011). Other commercial initiatives include the Dutch company Biorefinery Solutions that develops biorefining technologies to extract proteins from fresh plant materials, such as vegetable trimmings and other side streams (Biorefinerysolutions.com) (Figure 1). In the UK, an alliance of Biorefining Centers, BioPilotsUK, was launched recently to develop bio-based value chains across the UK (biopilotsuk.com). The latter alliance recognizes that development of commercially competitive biorefineries requires partnerships, including technology partnerships, and partnering for increasing knowledge and capabilities in the biorefineries. Hence, there are currently several commercial efforts underway, in Europe and elsewhere, but not all the processes and products mentioned have reached full commercialization stage production and market penetration as yet.

Biorefining aligns completely with the sustainable development goals as well as with the (circular) Bioeconomy, encompassing that more parts of both the food and feed crop plants and the non-food crop plants can be used as basis for new value added bio-based products (crop residues, industrial side streams and wastes), and that new materials, for example new types of plant biomass or biomass of marine origin, can be processed for value addition and sustainability gains (Figure 1).

If we do not take advantage of new bioprocessing technologies for biorefining we will soon globally lose even more of what could be used for feeding a rising global population.

When evaluating the sustainability of new biobased products, derived from biorefining of biomass and agroindustrial side streams, we need to answer the key questions: Is it environmentally, economically and socially sustainable? Further, when it comes to Food Safety of the new biobased products, we also have to address whether such new biobased products are safe, healthy and nutritious?

\section{Future trends}

2.1 The potentials: It is the inherent intactness of the complexity in fresh plant materials (plant cell walls, proteins and storage polymers) as compared to the structural simplicity of fossil oil, which opens up for producing a wide spectrum of higher value products; products where it is not just the energy content which is used, but also the molecular complexity of proteins, oligosaccharides, and metabolites, e.g. antioxidants which is advantageously used to create useful products. For example, accumulation of gut-beneficial fructooligosaccharides in many cereal forage crops allows for these crops to be used as natural sources for industrial production of fructooligosaccharides (lanucci et al., 2016). Other reported examples include direct extraction of proteins and phenols from rapeseed stems and leaves by pulsed electric fields technology (Yu et al., 2015), as well as enzyme assisted simultaneous extraction of potentially prebiotic xylooligosaccharides and antioxidant phenolics (hydroxycinnamic acids) from different types of biomass streams using enzymes derived from a particular Bacillus subtilis strain (Reddy and Krishnan, 2016). These processes and products, and 
most of those to be mentioned in the following sections, are currently at a proof-of-concept stage, and have been published in the research literature. Processing cost assessments, cost-volume-profit analyses, distance to market, and full sustainability and safety assessments have not been disclosed (or have not been done yet). The cases above and those to be outlined in the following nevertheless exemplify how biorefining of side streams and upgrading of new biomass sources cannot only substitute for fossil-based products but also provide the basis for new products, e.g. food and feed ingredients and new functional materials.

2.2 The yellow biorefinery is the most well described biorefinery. The feedstock used is the recalcitrant and dry biomass of e.g. straw, corn stover and wood chips. Until quite recently, the sole focus of the Yellow Biorefinery was to convert the feedstock as efficiently as possible into biofuel, notably ethanol. For such biorefinery conversion an efficient physico/chemical pre-treatment is needed in order to make the cellulose amendable to enzymatic attack and degradation. The pretreatment is followed by an enzyme treatment, using a carefully designed blend of enzymes, hereby opening the plant cell wall structures and breaking down the plant polymers to monosaccharides. Lastly fungal yeast cells can be grown on the monosaccharides and produce bioethanol. However, new pre-treatments and processing regimes, and new types of enzyme and product development and recovery technologies have opened for using all major components of the lignocellulosic plant materials to create new products:

The lignin can be used for production of higher value products like binders and coatings and also as a food flavour ingredient, e.g. by conversion parts of the lignin into vanillin (Fache et al., 2016). The hemicellulose polymer network of straw, stovers and wood, can be converted by enzymatic processing to specific small oligos, e.g. xylooligosaccharides. Such xylan-derived oligosaccharides have been shown to have prebiotic potential in various in vitro experiments by stimulating the growth of putative probiotic bacteria, e.g. Lactobacillus brevis (Faryar et al. 2015), and various Bifidobacterium spp. dependent on the degree of arabinosyl-substitutions on the xylan backbone (Pastell et al., 2009). Very recently, we discovered that enzymatically released xylooligosaccharides from hydrothermally pretreated wheat straw might be promising prebiotics for pigs by reducing growth of potentially undesirable bacteria such as Clostridium perfringens as observed in pig gut microbiota fermentations (Dotsenko et al., 2018).

With regard to safety, it is important to add that among various biomass pretreatment regimes, a hydrothermal pretreatment, involving treatment of the biomass with steam, has been widely used in commercial pilot cellulosic ethanol production facilities as a first step in preparing the lignocellulosic biomass for upgrading and refining (Larsen et al., 2012). Whilst fungal contamination including potential mycotoxin production in the feedstock might be an issue, the hydrothermal pretreatment essentially sterilizes the biomass material abolishing this risk factor as a concern in relation to biorefinery production of food or feed components from the biomass. However, the hydrothermal pretreatment is accompanied by production of furans from both glucose and and pentoses as well as a series of oligophenolic compounds resulting from pentose self-condensation reactions (Rasmussen et al., 2017). These latter compounds are known to be potent cellulase inhibitors, but there is presently no knowledge of their potential toxicity aspects should they end up in edible products via further biomass biorefining. Considering the concerns generated when the formation of acrylamide in fried potatoes was discovered as being potentially toxic and subsequently discovered to be formed during thermal processing of many other food products (Gökmen, 2014) it is evident that the safety of thermally generated carbohydrate degradation products from biomass pretreatment should be investigated in relation to using yellow biomass biorefinery products in food or feed. 
2.3 Food and feed ingredients from the green biomass: Green grass can be grown to produce twice as much biomass per hectare as compared to cereals (Jørgensen \& Lærke, 2016); several harvests can be made annually; and due to a strong root structure throughout the year, run-off of nutrients from the field, potentially polluting rivers, lakes and inner shallow waters, can be cut to half per hectare and one fourth per produced tonnes. The green grass as feedstock provides basis for protein rich animal feed ingredients as well as prebiotic feed composition (Dotsenko \& Lange, 2017). Hence, xylooligosaccharides with potential prebiotic activity can be extracted enzymatically from ryegrass (Dotsenko et al., 2018). At present, the latter potential for prebiotic functionality has been demonstrated only in vitro and based on lab-scale experiments. Clinical safety assessments and functionality tests in animal or even humans have not been reported as yet, and similar to the case of yellow biomass, any possible carbohydrate degradation products from a pretreatment must also be considered in safety assessments.

2.4 Agroindustral side streams as new biorefinery feedstocks: High value addition potentials have already been identified for the side streams of e.g. potato starch and sugar beet processing (as mentioned in section 1.). New processes and products have also been suggested for cereal processing side streams from e.g. wheat starch processes (wheat bran is a side stream) and beer brewing (brewer's spent grain is a side stream). Hence, production of prebiotic arabinoxylans have been suggested from such industrial cereal processing streams (Mendis, Simsek, 2014), and recently a novel integrated process employing enzymatic carbohydrate biorefining and anionic exchange separation has been published for fractionation of wheat bran arabinoxylan carbohydrates and ferulic acid (Dupoiron et al., 2017). Also, a techno-economic assessment has shown that integrated production of xylitol, ethanol, and polyhydroxybutyrate from brewer's spent grain can add value, and notably that such biorefinery-based production of xylitol, which can be used as a sweetener in food products, is feasible from both an economic and energy-point of view (Davila et al., 2016). Recently enzymatic processing of soybean flakes has also opened up for new uses of soypolysaccharide-materials, which are co-processing products from soy protein processing (Pierce et al., 2017).

\subsection{The red biorefinery, upgrading slaughterhouse side- and waste streams: Modern} slaughterhouses are highly efficient; and a very high proportion of the animal is used. However, some products remain underexploited or the disposal is expensive or causing environmental pollution: for example, feathers from chickens and bristles from pigs may be converted into proteinrich animal feed. New enzyme discoveries opens for such improved processing upgrading animal waste to protein-rich animal feed (Lange et al., 2016). Blood from livestock and pigs can be used as basis for pharma products, beneficial for people (especially women) with iron deficiency (Anon. 2017). In Denmark for example, the blood from pig abattoirs is already fractionated into a variety of food and feed ingredients. The production of these blood-derived products is continuously subject to national and other regulatory control measures, eg at the EU level, to ensure that the highest level of hygiene measures are met and to prevent pathogen transfer and disease.

2.6 The milk biorefinery: The protein and lactose of the whey resulting after cheese making have been developed into a range of value added products within food ingredients (functional ingredients as well as nutritious ingredients (Anon. 2017)). This upgrading of whey has reached full commercial scale and viability, and product safety measures and product safety monitoring are in place.

2.7 Food and feed ingredients from the Blue Biomass: The marine biomass comprises four major but very different types of biorefinery feedstocks: 1 . Cut offs (head and tails; backbones) and innards 
from fish processing and bycatch; 2 . The brown, red, and green macroalgae/seaweed 3. Biomass of mussels; and 4. Biomass of invertebrates e.g. mollusks. From the marine animal-based feedstocks the main product is fish peptides, protein hydrolysates (including the recalcitrant collagen hydrolysate); and omega 3 lipids. Fish innards may be used for extraction of several valuable products (from e.g. cod liver; and oil from herring and mackerel). The use of fish oil in food products or as food supplements is already established. Due to the oxidative vulnerability of omega 3 lipids, and the possible safety concerns related to the lipid oxidation products, the oxidative protection of these products in foods and feed (including e.g. pet foods) is continuously being investigated (Jacobsen, 2016; Thomsen et al. 2017). Like other products, the use of such fish-derived oils and hydrolysates in food and feed will obviously also be subject to careful safety testing and legislative control measures. The macroalgae have a spectrum of medium to high level potential components (fucoidans, alginate, laminarin, and proteins) that can be gently extracted by enzyme technology (Rhein-Knudsen et al., 2015); products from macroalgae include a spectrum of health promoting or functional, proteinaceous products; plus many other value added products for e.g. wound and skin care.

2.8 Safety issues with regard to food and feed ingredients from biorefining. This area requires attention and careful studies. A classical issue is the need for monitoring of cyanide in cassava processing pulp and of potentially toxic (mainly as goitrogens) glucosinolates in rapeseed cake. Also, in relation to biorefining of agroindustrial co-processing products for food and feed uses, attention must be given to e.g. potentially antinutritional and off-taste components in seeds and, as mentioned above, to thermal carbohydrate degradation compounds in biorefinery extracts and products from thermally pre-treated plant biomass. More focus on such issues as well as on safety issues in general is required in the next wave of research. Special attention should be given to minor components that may be present in the biomass and potentially in the biorefinery products. It is important to ensure that biorefining does not lead to products where specific harmful components are up-concentrated to undesirable levels in relation to safety of the products produced.

2.9 Regulatory obstacles for approval of new, bio-based products: Obstacles are met when attempting to improve resource efficiency and reducing waste streams by upgrading food components which earlier have been categorized as "waste“. Similarly, regulatory obstacles are also met where fully approved food products (like sweets) are off spec (broken packaging etc.). They cannot then be channelled into being used even for animal feed. Under EU regulations, any food that was not consumed "significantly" prior to May 1997 is considered as a novel food. The novel foods cover food from new sources, new substances used in foods as well as new ways and technologies for producing food, and are regulated by the European Food Safety Authority (EFSA).

Regulatory issues occur as obstacles when new attempts are taken to improve the circularity of the food chain: a restaurant brings back their surplus food for the chicken farm, where they get their eggs and chicken, to use as chicken feed. This may in EU, not be ranked as a regulatory-accepted practice. Revisiting the regulatory "Waste" directives is needed, to ensure both full safety precautions and opening for circularity where the "waste" is actually a clean food or feed compatible resource but just not made use of earlier.

In Europe, many research calls within the biorefinery field now emphasize that the research and the ensuing industrial process and product development to be conducted must target one or more of the 17 Sustainability goals outlined by the UN. 


\section{Conclusions}

The Hypothesis: It is possible to make an entire spectrum of food and feed ingredients from bioprocessing of terrestrial and aquatic biomass as explained and exemplified in the present treatise. The conclusion is that upgrading of hitherto underexploited parts of the food materials and agroindustrial processing residues can provide basis for value added food and feed ingredients. This contributes to feeding the world in a sustainable way -getting more out of the land and the water already used for the primary production.

Applications: Such biobased food and feed ingredients may be shown to represent very high value, when documented to be improving health of humans or of animals. For the latter special interest are drawn to the potentials of producing prebiotic foods to people, improving their robustness through improved gut health; and of producing feed to pigs, chicken and fish with the potential effect that less antibiotics or less zinck is needed. New business models, alliances, and technology partnerships within biorefining may open for revenue sharing through the entire value chain.

R\&D needs: Processing of biomass in a biorefinery effort to obtain a fan of products and attain improved resource utilization is closely tied to the use of efficient enzymes. Hence, biorefinery developments targeted at developing new processes and new food and feed products in a circular bioeconomy also calls for discovery and development of new, efficient enzymes for such processes. There is also an urgent need to strengthen the research and development within food and feed ingredients with particular gut health promoting (prebiotic) effects; and within e.g. securing the quality of nutritious components extracted from green or blue biomass for feed and food purposes. It is desirable to strengthen the research and development efforts towards a broader range of health promoting effects, especially promising from marine macroalgae biomass, and certainly with focus on safety and sustainability issues. 


\section{References}

Anon. (2017). Nordic Bioeconomy - 25 cases for sustainable change, Copenhagen. Available at: https://doi.org/10.6027/ANP2016-782 /Accessed 16.06.17

Davila, J.A., Rosenberg, M., Cardona, C.A. (2016). A biorefinery approach for the production of xylitol, ethanol and polyhydroxybutyrate from brewer's spent grain. AIMS Agricult. Food 1, 52-66.

Dotsenko, G., Lange, L. (2017). Enzyme enhanced protein recovery from green biomass pulp. Waste Biomass Valor, 8, 1257.

Dotsenko, G., Meyer A.S., Canibe, N., Thygsen, A., Nielsen, M.K., Lange, L. (2018). Enzymatic production of wheat and ryegrass derived xylooligosaccharides and evaluation of their in vitro effect on pig gut microbiota. Biomass Conv. Bioref. https://doi.org/10.1007/s13399-017-0298-y (in press)

Dupoiron, S., Lameloise, M.-L., Pommet, M., Bennaceur, O., Lewandowski, R., Allais, F., Teixeira, A.R.S., Remond C., Rakotoarivonina H. (2017) A novel and integrative process: From enzymatic fractionation of wheat bran with a hemicellulasic cocktail to the recovery of ferulic acid by weak anion exchange resin. Industr. Crops Prod. 105, 148-155.

Fache, M., Boutevin, B., Caillol, S. (2016). Vanillin production from lignin and its use as a renewable chemical. ACS Sust. Chem Eng. 4, 35-46.

Faryar, R., Linares-Pasten, J.A., Immerzeel, P., Mamo, G., Andersson, M., Stalbrand, H., Mattiasson, B., Karlsson, E.N. (2015). Production of prebiotic xylooligosaccharides from alkaline extracted wheat straw using the K80R-variant of a thermostable alkali-tolerant xylanase. Food Bioprod. Proc. 93, 110.

Gökmen, V. (2014) A perspective on the evaluation of safety risks in thermal processing of foods with an example for acrylamide formation in biscuits. Qual. Assur. Safety Crops Foods 6, 319-325.

Holck, J., Hjernø, K., Lorentzen, A., Vigsnæs, L. K., Hemmingsen, L., Licht, T. R., Mikkelsen, J. D., Meyer, A. S. (2011). Tailored enzymatic production of oligosaccharides from sugar beet pectin and evidence of differential effects of a single DP chain-length difference on human fecal microbiota composition after in vitro fermentation. Process Biochem, 46, 1039-1049.

lanucci, A., Pizzillo, M., Annicchiarico, G., Fragasso, M., Fedele, V. (2016). Dynamics of accumulation and partitioning of dry matter and fructo-oligosaccharides in plant fractions of forage cereals. Experim. Agric. 52, 188-202.

Jacobsen, C. 2016 Oxidative Stability and Shelf Life of Food Emulsions. in Oxidative Stability and Shelf Life of Foods Containing Oils and Fats. Academic Press, pp. 287-312.

Jørgensen U., Lærke P.E. (2016) Perennial Grasses for Sustainable European Protein Production. In: Barth S., Murphy-Bokern D., Kalinina O., Taylor G., Jones M. (eds) Perennial Biomass Crops for a Resource-Constrained World. Springer, Cham.

King, D., Hagan, A. (2010). The future of industrial biorefineries, World Economic Forum, Geneva Switzerland. 
Lange, L., Huang, Y., Busk, P. K. (2016). Microbial decomposition of keratin in nature -new hypotheses with industrial relevance. Appl. Microbiol. Biotechnol., 100, 2083-2096

Larsen, J., Haven. M.Ø., Thirup. L. (2012). Inbicon makes lignocellulosic ethanol a commercial reality. Biomass Bioenerg., 46, 36-45.

Mendis, M., Simsek, S. (2014) Arabinoxylans and human health. Food Hydrocoll., 42, 239-243.

Pastell, H., Westermann, P., Meyer, A.S., Tuomainen, P., Tenkanen, M. (2009). In vitro fermentation of arabinoxylan-derived carbohydrates by Bifidobacteria and mixed fecal microbiota. J. Agric. Food Chem. 57, 8598-8606.

Pierce, B., Agger, J. W., Wichmann, J., Meyer, A. S. (2017). Oxidative cleavage and hydrolytic boosting of cellulose in soybean by Trichoderma reesei Cel61A lytic polysaccharide monooxygenase. Enz. Microb. Technol., 98, 58-66.

Rasmussen, H., Tanner, D., Sørensen, H.R., Meyer, A. S. (2017). New degradation compounds from lignocellulosic biomass pretreatment: routes for formation of potent oligophenolic enzyme inhibitors. Green Chem., 19, 464-473.

Reddy, S.S., Krishnan, C. (2013). Characterization of enzyme released antioxidant phenolic acids and xylooligosaccharides from different Graminaceae or Poaceae members. Food Biotechnol. 27, 357370.

Rhein-Knudsen, N., Ale, M. T., Meyer, A. S. (2015) Seaweed hydrocolloid production: An update on enzyme assisted extraction and modification technologies. Mar. Drugs 13, 3340-3359.

Thomassen, L. V., Vigsnæs, L. K., Licht, T. R., Mikkelsen, J. D., Meyer, A. S. (2011). Maximal release of highly bifidogenic soluble dietary fibers from industrial potato pulp by minimal enzymatic treatment. Appl. Microbiol. Biotechnol., 90 (3), 873-884.

Thomsen, B.R., Griinari, M., Jacobsen, C. (2017). Improving oxidative stability of liquid fish oil supplements for pets. Eur. J Lipid Sci. Technol. 119 (6), [e201600492]

UN Sustainable Develpment Goals: http://www.un.org/sustainabledevelopment/sustainabledevelopment-goals// Accessed 16.06.17

Waglay, A., Karboune, S. (2017). A novel enzymatic approach based on the use of multi-enzymatic systems for the recovery of enriched protein extracts from potato pulp, Food Chem., 220, 313-323.

Yu, X., Bals, O., Grimi, N., Vorobiev, E. (2015). A new way for the oil plant biomass valorization: Polyphenols and proteins extraction from rapeseed stems and leaves assisted by pulsed electric fields. Industr. Crops Prod., 74, 309-318. 
Figure legend:

Figure 1. Bioeconomy graphic depicting biorefining of plant, animal, and marine materials in a long term global sustainable development context, introducing the improved utilization of currently used raw materials, i.e. processing residues, as well as use of new raw materials, i.e. especially materials of marine origin. Graphic reproduced with permission from Biorefinery Solutions BRS, Groenlo, Holland (biorefinerysolutions.com/bio-economy). 


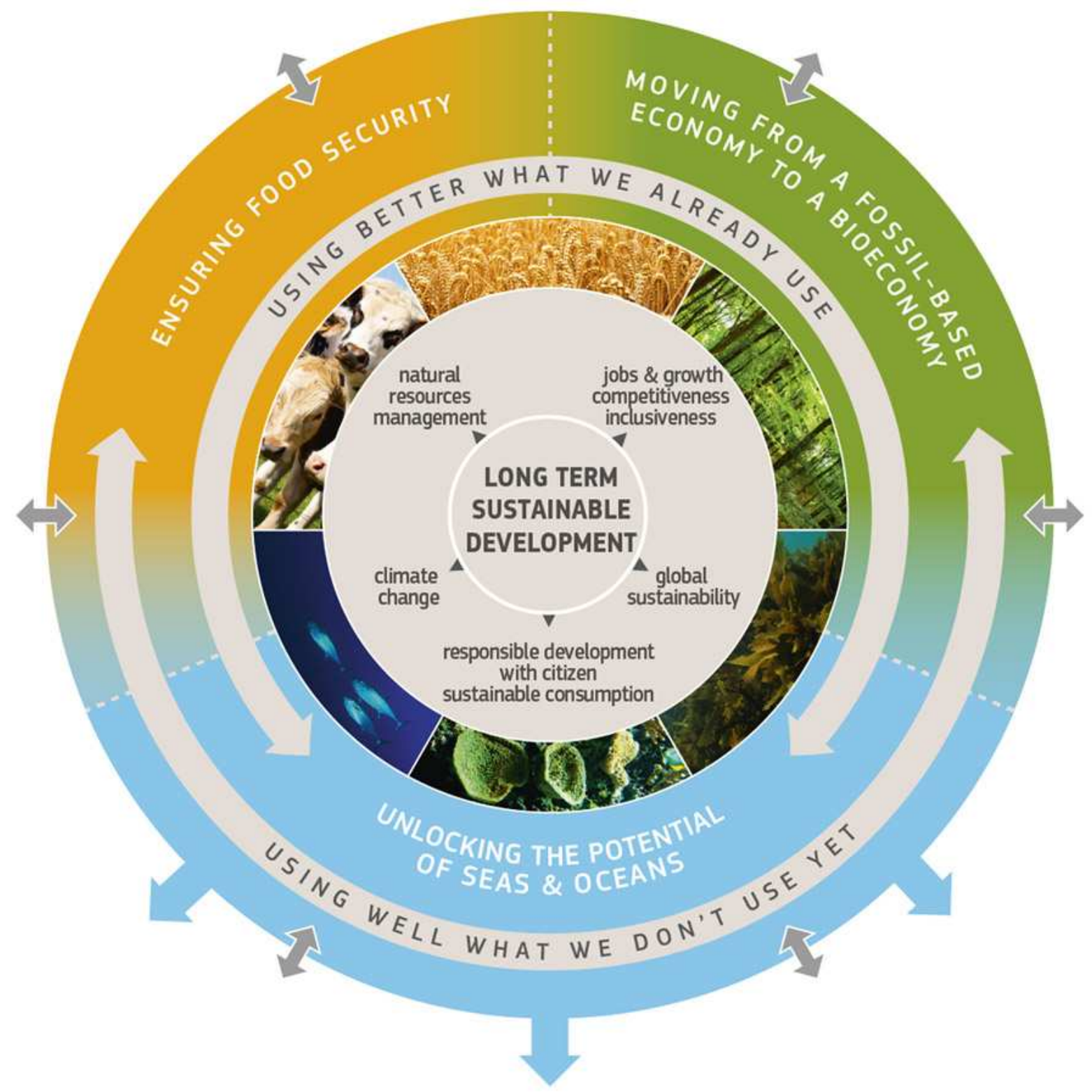

Figure 1. 


\section{Highlights}

- Biorefining of food processing side streams can create value and reduce waste

- Biorefining of plant and marine biomass can contribute to sustainable development

- Biocatalytic processing can release useful products from agroindustrial resources

- Biorefinery products of thermally pretreated plant biomass deserve safety investigation

- Current regulatory obstacles exist preventing circularity in the food chain 